\title{
Preparation and Performance of Short Carbon Fiber and Flake Graphene Reinforced Polycarbonate Composites: Effects of Different Tougheners
}

\author{
Zhixing Yu*, Yu Bai, Yingcheng Li, Wei Wang, James H. Wang \\ R \& D Division for Synthetic Polymers, Sinopec Shanghai Research Institute of Petrochemical Technology, Shanghai, China \\ Email: *yvzx.sshy@sinopec.com
}

How to cite this paper: Yu, Z.X., Bai, Y., Li, Y.C., Wang, W. and Wang, J.H. (2018) Preparation and Performance of Short Carbon Fiber and Flake Graphene Reinforced Polycarbonate Composites: Effects of Different Tougheners. Journal of Materials Science and Chemical Engineering, 6, 81-89.

https://doi.org/10.4236/msce.2018.67009

Received: June 5, 2018

Accepted: July 1, 2018

Published: July 4, 2018

\begin{abstract}
Different tougheners including methyl methacrylate-butadiene-styrene terpolymer (MBS, core-shell type), maleic anhydride (MAH) grafted ethylene-octene copolymer (EOM), and MAH grafted polyethylene wax (PEM) were investigated for toughening the polycarbonate $(\mathrm{PC})$ composites reinforced by short carbon fiber (SCF) and flake graphene (FG). The effects of tougheners on the preparation, thermal conductivity and mechanical properties of PC composites were studied. Scanning electron microscopy was used for characterizing the impact fracture surfaces of the composites. The results showed that introducing tougheners into the carbon reinforced PC composites was beneficial to improving the processability, and PEM was more effective than EOM and MBS. Meanwhile, the through-thickness and the in-plan thermal conductivity decreased to some degree due to the isolated island effects of tougheners. Moreover, the brittle PC composites with high flexural stress could be easily toughened by tougheners. In contrast, PEM had better toughening function than EOM and MBS, and correspondingly, the stiffness of the composites was the lowest for the PEM toughened systems. The fractography revealed that dense and uniformly distributed carbon fillers dispersed in matrix PC and circular cavities coexisted in the composites. The naked fiber length gradually increased as the ductility of composite materials improved.
\end{abstract}

\section{Keywords}

Toughener, Processability, Thermal Conductivity, Mechanical Property, Fractography 


\section{Introduction}

Carbon materials, such as carbon fiber, carbon nanotube, graphene, etc., have been commonly studied for enhancing the mechanical, electrical and thermal properties of thermoplastic or thermosetting resins. These modified composites generally exhibit low thermal expansion, light-weighting, good heat dissipation, high stiffness, and can be potentially applied in integrated circuits, satellite devices, electrnonics packaging and encapsulation, and thermal management fields where higher thermal conductivity required [1] [2] [3] [4] [5].

Generally speaking, factors determining the thermal and mechanical properties of composites include the surface treatment and interfacial structure, alignment and packing structure, aspect ratio, volume fraction, size, shape, purity, polydispersity and intrinsic conductivity of fillers, etc. [6] [7] [8] [9]. However, the surface of pristine carbon materials is non-polar and chemically inert. As a result, the interfacial force between short carbon fibers and polymer matrix is quite weak, which tends to decrease the thermal and mechanical properties of composites. As a result, filler modification, matrix modification and interfacial modification approached were developed and found to effective in remarkably improving the properties of polymer composites [10] [11] [12].

At the same time, heterogeneous or hybrid fillers have been demonstrated as another effective method for enhancing the thermal and mechanical properties of polymer composites [6] [10] [13]. Two or more fillers with different size, shape showed a positive synergic effect on thermal conductivity and mechanical strength of composites [14] [15] [16].

Polycarbonate-based thermoplastic composites have been prepared and studied using different carbon materials as modifying fillers [17] [18] [19]. However, they usually showed low impact strength and obviously brittle behaviors [15] [16] [19]. In this work, MBS, EOM and PEM were used for toughening the PC composites reinforced by SCF and FG. The preparation, thermal conductivity, mechanical properties, and fracture mechanism of PC composites were studied.

\section{Experimental}

\subsection{Preparation of Polycarbonate Composites}

First, confirm that you have the correct template for your paper size. This template has been tailored for output on the custom paper size $(21 \mathrm{~cm} * 28.5 \mathrm{~cm})$. A fixed quantity of silane coupling agent (SCA) was dispersed in the white oil (WO), and the obtained solution was poured into the FGs and SCFs. Stir the mixture until fully mixed. The modified fillers were proportionally mixed with the dried PC pellets and/or toughening agent (TA) for 3 minutes by a high speed mixer. The compound was melt blended in a twin-screw extruder (Leistritz, German) to prepare PC composites. The compositions of the PC composites prepared are listed in Table 1 . The processing temperature was $280^{\circ} \mathrm{C}$ and the screw speed was $150 \mathrm{rpm}$. Then the composites were dried under vacuum and molded using an injection machine (BOY, German) for measurements. 
Table 1. Compositions of PC composites modified by different tougheners.

\begin{tabular}{ccccccc}
\hline \multirow{2}{*}{ Formula } & \multicolumn{6}{c}{ Content $($ weight, \%) } \\
\cline { 2 - 7 } & PC & TA & SCF & FG & SCA & WO \\
\hline Control & 70 & 0 & 25 & 5 & 0.3 & 1.6 \\
+ HBS & 65 & 5 & 25 & 5 & 0.3 & 1.6 \\
+ EOM & 65 & 5 & 25 & 5 & 0.3 & 1.6 \\
+ +PEM & 65 & 5 & 25 & 5 & 0.3 & 1.6 \\
\hline
\end{tabular}

\subsection{Laboratory Tests}

Differential scanning calorimetry (DSC): The melting behaviors of the PC composites using different tougheners were determined using a differential scanning calorimeter (TA Instruments, USA). Experiments were performed with about 5 mg samples under dry nitrogen gas condition. First, the sample was heated to $200^{\circ} \mathrm{C}-250^{\circ} \mathrm{C}$ at a rate of $10^{\circ} \mathrm{C} / \mathrm{min}$ and then held at $200^{\circ} \mathrm{C}-250^{\circ} \mathrm{C}$ for $1 \mathrm{~min}$. Subsequently, the sample was cooled at a rate of $10^{\circ} \mathrm{C} / \mathrm{min}$ to $-50^{\circ} \mathrm{C}$ and held at $-50^{\circ} \mathrm{C}$ for $1 \mathrm{~min}$. It was then scanned from $-50^{\circ} \mathrm{C}$ to $250^{\circ} \mathrm{C}-300^{\circ} \mathrm{C}$ at a heating rate of $10^{\circ} \mathrm{C} / \mathrm{min}$. The melting temperature or glass transition temperature was obtained from the second-heating thermogram.

Thermal conductivity: In-plane and through-thickness thermal conductivity data of the composites were measured at $25^{\circ} \mathrm{C}$ by using a LFA467 laser flash analyzer (NETZSCH, Germany) according to ASTM E1461 standard. Square test samples with a dimension of $6 \mathrm{~mm} \times 6 \mathrm{~mm} \times 1 \mathrm{~mm}$ and a dimension of $10 \mathrm{~mm}$ $\times 10 \mathrm{~mm} \times 1 \mathrm{~mm}$ were used for testing, respectively.

Mechanical properties: Notched Izod impact strength was determined with a RESIL6957 impact tester (CEAST, Italy) according to ISO 179-1: 2010. The size of specimens was $80 \mathrm{~mm} \times 10 \mathrm{~mm} \times 4 \mathrm{~mm}$ and the depth of notch was $2 \mathrm{~mm}$. Flexural strength and modulus were measured on a 3344 universal material testing machine (Instron, USA) at a bending rate of $2 \mathrm{~mm} / \mathrm{min}$ and a span of 64 $\mathrm{mm}$ according to ISO 178-2010. The specimens had a size of $80 \mathrm{~mm} \times 10 \mathrm{~mm} \times$ $4 \mathrm{~mm}$. Not less than 5 specimens were used for each mechanical testing.

Morphology: Prior to scanning electron microscopy (SEM) observations, all fracture surfaces of the impact specimens were sputter-coated with gold. Fractographic studies with SEM were conducted on the fracture surfaces by a Merlin field-emission scanning electron microscope (FE-SEM) (Carl Zeiss, Germany).

\section{Results and Discussion}

\subsection{Processing Parameters of PC Composites}

PC composites reinforced by short carbon fiber and flake graphene and three kinds of tougheners were prepared by using a twin screw extruder to achieve high intensity mixing and good dispersion of the modifiers. The objective of this research was to enhance the toughness of the PC composites. Following the composite preparation, the thermal properties of the materials were characte- 
rized, the resulting DSC curves of untoughened and toughened composites are shown in Figure 1. The control composite had a glass transition temperature $\left(\mathrm{T}_{\mathrm{g}}\right.$ ) of $134.6^{\circ} \mathrm{C}$ and showed an amorphous behavior of polymer. The $\mathrm{T}_{\mathrm{g}}$ values of the PC composites toughened by MBS, EOM and PEM were $137.0^{\circ} \mathrm{C}, 141.0^{\circ} \mathrm{C}$ and $140.8^{\circ} \mathrm{C}$, respectively. The greater the temperature was, the more incompatible the $\mathrm{PC} /$ toughener composites were. In addition, the toughened composites by MAH grafting copolymers also displayed typical crystalline characteristics and the melting peak temperatures are $119.2^{\circ} \mathrm{C}$ and $102.1^{\circ} \mathrm{C}$ for EOM and PEM systems, respectively.

The melt temperature of PC composite and the torque of twin-screw extruder during the extrusion were recorded and summarized in Figure 2. The melt temperature of PC composite without tougheners was $283^{\circ} \mathrm{C}-285^{\circ} \mathrm{C}$ and the torque was $36 \%-55 \%$. When different tougheners are incorporated into PC composites, both melt temperature and torque decreased. In comparison, the MBS toughening agent showed only minor changes while the MAH grafted polyolefin, especially the PE wax toughening agent resulted in significant reduction. The melt temperature was $266^{\circ} \mathrm{C}-277^{\circ} \mathrm{C}$ and the torque was $11 \%-20 \%$ for

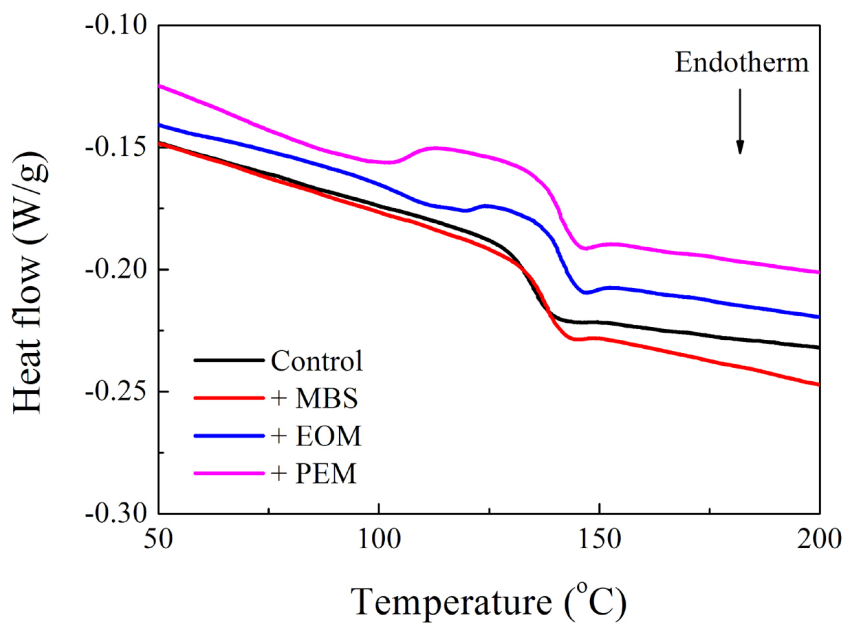

Figure 1. DSC second-heating curves obtained from PC composites.

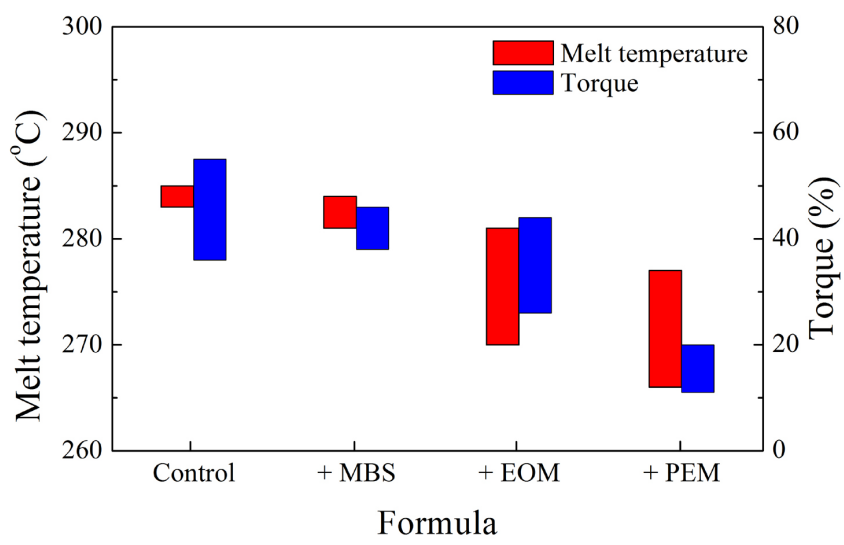

Figure 2. Process parameters of PC composites. 
the PE wax as toughening agent. In fact, PE wax is typically applied as a compatilizer or surface modifier in the composite materials. In this work, we found that $\mathrm{PE}$ was can effectively improve the processability of carbon materials filled $\mathrm{PC}$ composites. The lower parameter values of $\mathrm{PE}$ was system relative to $\mathrm{EO}$ copolymer system was mainly due to the difference in the melting points of $\mathrm{PE}$ wax and EO copolymer. The lower the melting temperature of toughener, the lower the parameter values, and the easier the composite preparation process. Moreover, a slightly reduced parameter values of MBS system as compared to the control case are probably due to the poor heat resistance properties of MBS.

\subsection{Thermal Conductivity of PC Composites}

For a polymer composite material to possess good thermal conductive properties, it needs an effective thermal conductive paths and network in its interior structures. The through-thickness and in-plane thermal conductivity data of the PC composites are shown in Figure 3. The values of the control sample filled by SCF and FG were 0.61 and $3.08 \mathrm{~W} / \mathrm{mK}$, respectively. The through-thickness thermal conductivity is much lower than the in-plane thermal conductivity. This indicates that PC composite is an anisotropic thermal conductive material. The key reason is that carbon fibers successively arrange along the flow direction, this is beneficial to the in-plane conductivity and leading to a decreased probability of inter-linking or contacting in through-thickness direction. Even though a certain amount of flake graphene is applied and filled into carbon fibers, the contribution to the through-thickness conductivity is insufficient [15]. When different tougheners are used, not only the through-thickness thermal conductivity but also the in-plan thermal conductivity decreased to some degree relative to the control case. This is largely attributed to the incompatibility between PC and tougheners. And the latter disperses in the PC matrix in the form of isolated islands and disrupts heat transfer process. Note that the PEM toughening system, it showed a relative higher through-thickness thermal conductivity than MBS and EOM, this is due to more insequent and transverse carbon fibers arrange in the matrix material and improve the through-thickness transmission capability. This will be discussed later.

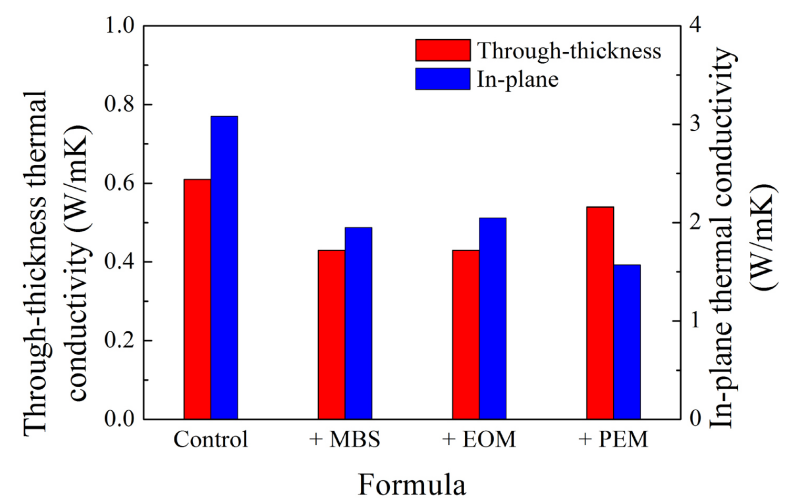

Figure 3. Thermal conductivities of PC composites. 


\subsection{Mechanical Properties of PC Composites}

Figure 4 shows the Charpy notched impact strengths of different PC composites with or without tougheners. As for the control sample, the impact strength is about $4.82 \mathrm{~kJ} / \mathrm{m}^{2}$. In comparison, as different tougheners are added to the composites, the impact strength properties were clearly improved. Among them, the PEM was most effective in enhancing impact strength, followed by EOM and then by MBS. The corresponding impact strengths were increased by $63.3 \%$, $25.7 \%$ and $7.7 \%$, respectively.

As shown in Figure 5, the flexural stress of the control sample increased linearly with the strain. The maximum stress reached $134.0 \mathrm{MPa}$ when the strain at failure was $1.7 \%$, and it showed an obviously brittle fracture mode. As for the MBS toughened system, as the strain increased, the flexural stress increase was slightly lower than the control sample, the maximum stress was 117.3 MPa. While the MAH grafted polyolefin tougheners were introduced, the PC composites exhibited a classical ductile bending deformation behavior. There existed an evident plateau region, that is, the stress remained constant as the strain increased. In comparison to EOM system having a maximum flexural stress of 71.8 $\mathrm{MPa}$, the more ductile PEM system displayed a lower maximum stress of only 61.8 MPa. However, a lowest strain at maximum stress for the PE wax system is probably caused by its low molecular weights and weak deformation ability and orientation under external forces.

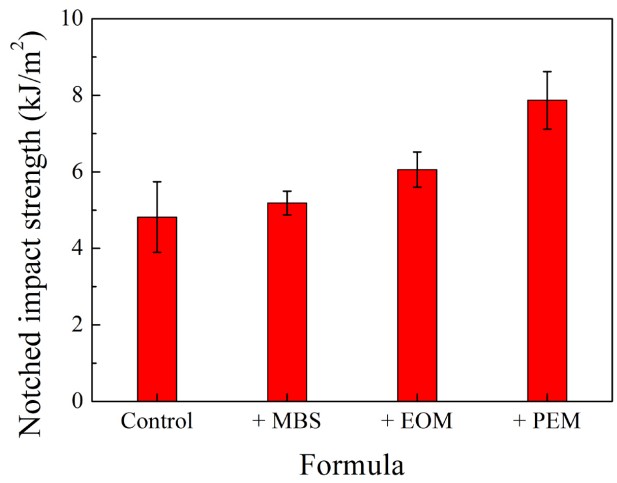

Figure 4. Charpy notched impact strengths of PC composites.

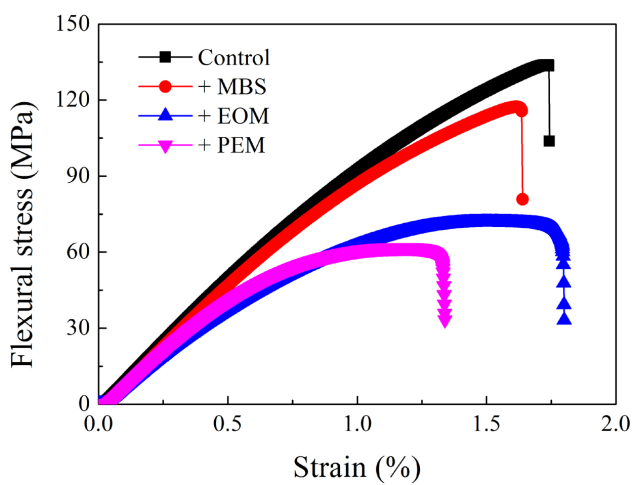

Figure 5. Flexural stress-strain curves of PC composites. 


\subsection{Fractography}

In order to explain the structure-property relationship observed above, Figure 6 shows the fractopraphic images of PC composites with or without toughening modification by observing fractural surface after impact tests. As can be seen in Figure 6(a), the carbon fibers dispersed uniformly in the PC matrix. And the fracture surface of the control sample was relative flat, indicating relatively brittle fracture mode. Besides, there existed many circular cavities, which could be resulted from fiber breaking or peeling from matrix under the external force [16]. However, the fracture surfaces of different toughener systems showed distinct morphologies from the control case in addition to cavitation. The length of the naked carbon fibers gradually increased when toughener changed from MBS, to EOM, and subsequently to PEM (Figures 6(b)-(d)). This can be explained by the decreased torque values of the toughened PC composite systems during extrusion. The smaller torque means lower shearing forces. Consequently, the damage to carbon fibers was reduced and the fibers kept relatively longer length. Massive longer fibers breaking and peeling from matrix inevitably absorbed more impact energy, and as a result, it displayed a correspondingly ductile fracture mode. Furthermore, Figure 6(d) also shows many insequent and transverse carbon fibers orientation on the surface of PE wax toughening system, which identified the enhanced through-thickness thermal conductivity.

\section{Conclusion}

Core-shell type and grafting type tougheners were applied for enhancing the

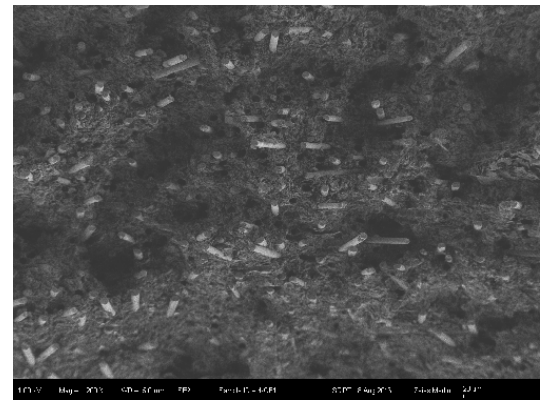

(a)

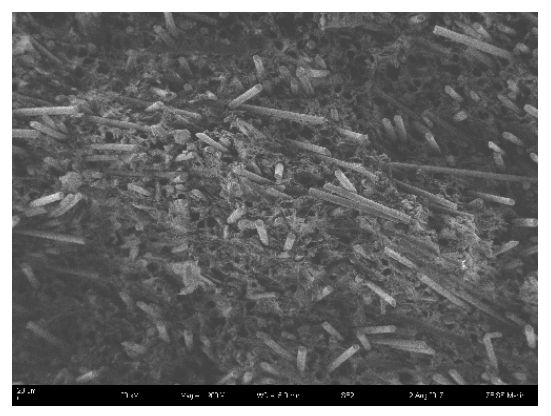

(c)

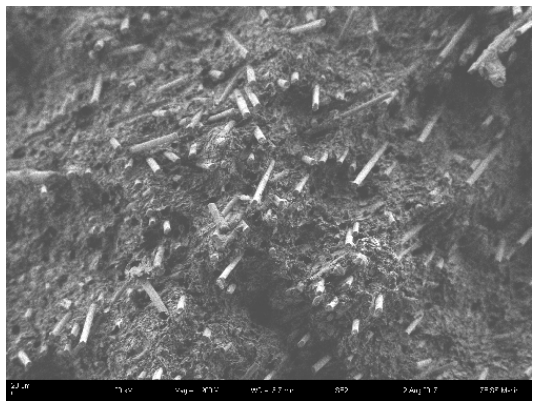

(b)

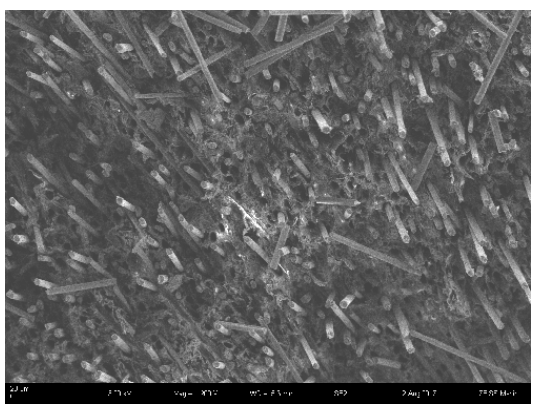

(d)

Figure 6. SEM images of PC composites (a) Control; (b) + MBS; (c) + EOM and (d) + PEM. 
toughness of SCF and FG reinforced PC composites. These tougheners were found to be effective in reducing the melt temperatures and torque during the extrusion process of the composites, and helped to improve the preparation process of composites. Unfortunately, tougheners are incompatible with PC matrix and formed isolated islands in matrix. The thermal conductivity of the toughened composites, either in parallel or perpendicular to extrusion direction, was found to decrease in the presence of a toughener. At the same time, the toughening effect of PEM was better than that of EOM, and MBS has lowest toughening effectiveness. The trend of flexural stress was opposite as the toughening effectiveness. The ductile composites displayed fiber breaking and peeling from PC matrix and cavitation, accompanied with the gradually increased length of naked fibers in the toughen composites.

\section{Acknowledgements}

The authors thank Dr. Yu Wang for the morphology characterization and the reviewers for the helpful discussions and suggestions.

\section{References}

[1] Fu, S.Y., Lauke, B. and Mai, Y.W. (2009) Science and Engineering of Short Fibre Reinforced Polymer Composites. Woodhead Publishing, 80-118. https://doi.org/10.1533/9781845696498.80

[2] Li, F., Hua, Y., Qu, C.B., Xiao, H.M. and Fu, S.Y. (2016) Greatly Enhanced Cryogenic Mechanical Properties of Short Carbon Fiber/Polyethersulfone Composites by Graphene Oxide Coating. Composites Part A: Applied Science and Manufacturing, 89, 47-55. https://doi.org/10.1016/j.compositesa.2016.02.016

[3] Leveuf, L., Marco, Y., Le Saux, V., Navrátil, L., Leclercq, S. and Olhagaray, J. (2018) Fast Screening of the Fatigue Properties of Thermoplasctics Reinforced with Short Carbon Fibers Based on Thermal Measurements. Polymer Testing, 68, 19-26. https://doi.org/10.1016/j.polymertesting.2018.03.045

[4] Zhao, Z.K., Du, S.S., Li, F., Xiao, H.M., Li, Y.Q., Zhang, W.G., Hu, N. and Fu, S.Y. (2018) Mechanical and Tribological Properties of Short Glass Fiber and Short Carbon Fiber Reinforced Polyethersulfone Composites: A Comparative Study. Composites Communications, 8, 1-6. https://doi.org/10.1016/j.coco.2018.02.001

[5] Ngo, I.L. and Byon, C. (2016) A Review on Enhancing Thermal Conductivity of Transparent and Flexible Polymer Composites. Science of Advanced Materials, 8, 257-266. https://doi.org/10.1166/sam.2016.2476

[6] Zabihi, Z. and Araghi, H. (2017) Effective Thermal Conductivity of Carbon Nanostructure Based Polyethylene Nanocomposite: Influence of Defected, Doped, and Hybrid Filler. International Journal of Thermal Sciences, 120, 185-189. https://doi.org/10.1016/j.ijthermalsci.2017.06.010

[7] Zare, Y. and Rhee, K.Y. (2017) Development of a Conventional Model to Predict the Electrical Conductivity of Polymer/Carbon Nanotubes Nanocomposites by Interphase, Waviness and Contact Effects. Composites Part A: Applied Science and Manufacturing, 100, 305-312. https://doi.org/10.1016/j.compositesa.2017.05.031

[8] Ngo, I.L., Vattikuti, S.V.P. and Byon, C. (2017) A Modified Hashin-Shtrikman Model for Predicting the Thermal Conductivity of Polymer Composites Reinforced 
with Randomly Distributed Hybrid Fillers. International Journal of Heat and Mass Transfer, 114, 727-734. https://doi.org/10.1016/j.ijheatmasstransfer.2017.06.116

[9] Yoo, Y., Lee, H.L., Ha, S.M., Jeon, B.K., Won, J.C. and Lee, S.G. (2014) Effect of Graphite and Carbon Fiber Contents on the Morphology and Properties of Thermally Conductive Composites Based on Polyamide 6. Polymer International, 63, 151-157. https://doi.org/10.1002/pi.4534

[10] Fan, B., Liu, Y., He, D. and Bai, J. (2017) Enhanced Thermal Conductivity for Mesophase Pitch-Based Carbon Fiber/Modified Boron Nitride/Epoxy Composites. Polymer, 122, 71-76. https://doi.org/10.1016/j.polymer.2017.06.060

[11] Burger, N., Laachachi, A., Ferriol, M., Lutz, M., Toniazzo, V. and Ruch, D. (2016) Review of Thermal Conductivity in Composites: Mechanisms, Parameters and Theory. Progress in Polymer Science, 61, 1-28. https://doi.org/10.1016/j.progpolymsci.2016.05.001

[12] Yao, S.S., Jin, F.L., Rhee, K.Y., Hui, D. and Park, S.J. (2017) Recent Advances in Carbon-Fiber-Reinforced Thermoplastic Composites: A Review. Composites Part B: Engineering, 142, 241-250. https://doi.org/10.1016/j.compositesb.2017.12.007

[13] Yu, G.C., Wu, L.Z. and Feng, L.J. (2015) Enhancing the Thermal Conductivity of Carbon Fiber Reinforced Polymer Composite Laminates by Coating Highly Oriented Graphite Films. Materials \& Design, 88, 1063-1070. https://doi.org/10.1016/j.matdes.2015.09.096

[14] Weber, E.H., Clingerman, M.L. and King, J.A. Thermally Conductive Nylon 6,6 and Polycarbonate Based Resins. I. Synergistic Effects of Carbon Fillers. Journal of Applied Polymer Science, 88, 112-122. https://doi.org/10.1002/app.11571

[15] Yu, Z., Bai, Y. and Wang, W. (2018) Thermal and Mechanical Properties of Thermal Conductive Composites Based on Polycarbonate. Petrochemical Technology, 47, 170-175. https://doi.org/10.3969/j.issn.1000-8144.2018.02.010

[16] Yu, Z., Bai, Y., Li, Y., Wang, X., Wang, W. and Liu, J. (2018) Fiber Length Distribution, Thermal, Mechanical and Morphological Properties of Thermal Conductive Polycarbonate/Chopped Carbon Fiber Composites. Polymer International. (In Press) https://doi.org/10.1002/pi.5628

[17] Gedler, G., Antunes, M., Borca-Tasciuc, T., Velasco, J.I. and Ozisik, R. (2015) Effects of Grapheme Concentration, Relative Density and Cellular Morphology on the Thermal Conductivity of Polycarbonate-Graphene Nanocomposites Foams. European Polymer Journal, 75, 190-199. https://doi.org/10.1016/j.eurpolymj.2015.12.018

[18] Sharma, S., Chandra, R., Kumar, P. and Kumar, N. (2015) Thermo-Mechanical Characterization of Multi-Walled Carbon Nanotube Reinforced Polycarbonate Composites: A Molecular Dynamics Approach. Comptes Rendus Mécanique, 343, 371-396. https://doi.org/10.1016/j.crme.2015.03.002

[19] Ozkan, C., Karsli, N.G., Aytac, A. and Deniz, V. (2014) Short Carbon Fiber Reinforced Polycarbonate Composites: Effects of Different Sizing Materials. Composites Part B: Engineering, 62, 230-235. https://doi.org/10.1016/j.compositesb.2014.03.002 